pool of principal investigators of NIH research projects are women. It is not known why so many women leave research. By aiming a programme at women who left science for family reasons, NIH hopes to test the theory that child-raising accounts for much of the attrition. The women's health office has already promised to fund the programme again in 1993 and, if its budget permits, in 1994.

Although NIH is praised by women for addressing an important problem, there are

\section{Number of female principal investigators still lags}

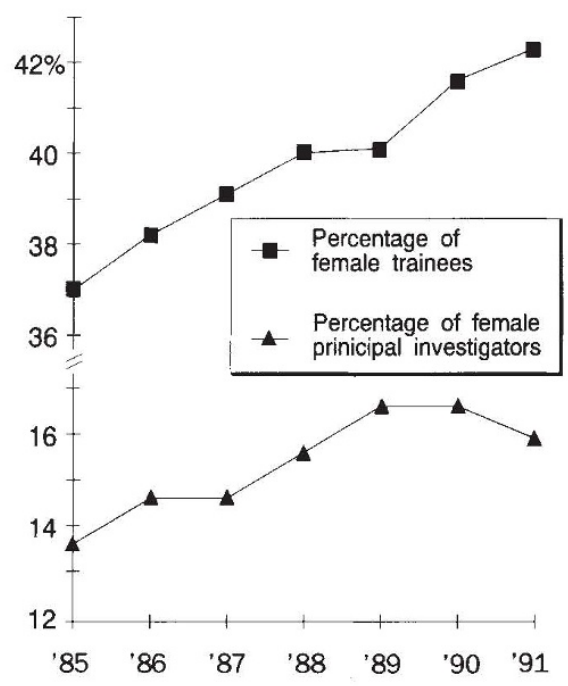

The percentage of women holding $\mathrm{NIH}$ trainee appointments still far exceeds the percentage of women receiving NIH research project grants. Both numbers have increased over the last 10 years, but the number of female principal investigators have failed to keep pace with the number of trainees.

questions about how well the programme will work. Time is short: the official announcement appeared only one month before the applications were due, and it has attracted little public notice. And the process of finding applicants is difficult. Walter Schaffer, an officer of the extramural research office, admits that "there isn't any really good way" for them to do so.

The most serious obstacle may be beyond NIH's control: will scientists be willing to take on women who, for five or ten years, have not read the literature and have had little contact with other researchers? "There is a real prejudice" towards people who lack the right training, says Catherine Didion, executive director of the Association for Women in Science in Washington DC. If so, NIH may find that the programme - at least in its current form - is not a true test of the existence of a pool of women hoping to return to science. Traci Watson

\title{
Hughes woos future MDs by offering space at bench
}

If widespread concern were all that mattered, the shortage of physicians entering biomedical research that has existed for the past 20 years would have been remedied long ago. But it has persisted despite several programmes by the US National Institutes of Health (NIH) to encourage MDs to undertake research.

Several years ago, the private sector decided to lend a hand. One such effort operates on the NIH campus itself: the Research Scholars Program, run by the Howard Hughes Medical Institute (HHMI). The institute, near NIH in Bethesda, Maryland, offers medical students a one-year sabbatical to do research in an NIH laboratory in the hope that students with firsthand experience in the laboratory will be more likely to carry out research after they graduate.

The programme, now seven years old, has placed 230 students from 73 medical schools in various NIH laboratories. It has proved so popular that HHMI has slowly expanded the class size from 23 to 50 , and some students, absorbed in their research, elect to stay a second year. Under a programme begun in 1989 , HHMI also awards one-year grants for medical students

to work at an academic or nonprofit research centre anywhere in the United States.

Created from a gift of Hughes Aircraft stock from its founder that has grown in value to over $\$ 6$ billion, HHMI supports the programme out of a conviction that physicians have an invaluable role in studying human health and disease. Hughes is also motivated by statistics showing that the percentage of MDs among applicants for research grants from NIH has dropped from 27 per cent in 1980 to 23 per cent in 1991 . Only 2.2 per cent of doctors spend most of their time in research, according to the American Medical Association.

One obstacle is the difference in the salaries of researchers and physicians an important issue for a medical student graduating with debts that average $\$ 50,000$. Another deterrent is the long training required to do research: medical training alone demands seven to eleven years, and many hesitate to postpone their careers by tacking on a few years of postdoctoral work. The Hughes programme addresses the problem of ignorance: medical schools make little provision for students to carry out research, and without such experience students lack sufficient information to choose between the laboratory and the bedside.

Students can put their medical background to the test in one of almost $300 \mathrm{NIH}$ laboratories under the guidance of a tenured investigator. Some participants start and complete their own projects during their stay, while others take over experiments already in progress. Students spend 40 to 80 hours per week in the laboratory and must give a presentation of their work to their fellow students. Participants live on the NIH campus in a beautiful former convent built in the 1920 s by the Sisters of the Visitation.

It is too early to judge the impact of the programme. Some of the members of the first class are still residents; of those who have finished, approximately half are doing postdoctoral research, including three who returned to NIH.

Whatever their motives, all appear to benefit from their year at NIH and to return to medical school with more knowledge about the causes of disease and the mechanisms of drugs. Even if the programme fails to swell the ranks of clinical investigators, few NIH officials would quarrel with the value of that outcome. Traci Watson

For more information about these programmes, contact Lainey Wittenberg, HHMI, One Cloister Court, Bethesda MD 20814-1460. 